\title{
Retraction Note to: Glyoxal modification mediates conformational alterations in silk fibroin: Induction of fibrillation with amyloidal features
}

\author{
SAuRAdipta BANERJEe (1) \\ Department of Biophysics, Molecular Biology and Bioinformatics, University of Calcutta, \\ Kolkata 700 009, India \\ (Email,dipta.saura@gmail.com) \\ Published online 11 November 2020
}

Retraction note to: J Biosci (2020) 45:32

https://doi.org/10.1007/s12038-020-0009-x

The Editor has retracted this article (Banerjee 2020) following an investigation conducted by the Indian Academy of Science which found overlap in text and images without proper attribution with the Ph.D. thesis of Dr. Priyanka Dubey (Dubey 2018). In addition to this, it was found that the affiliation stated in the article was not where the research was conducted. Because of these issues, the Editor has concluded that the results are not reliable. The author does not agree to this retraction.

\section{References}

Banerjee S. Glyoxal modification mediates conformational alterations in silk fibroin: Induction of fibrillation with amyloidal features. J Biosci 45, 32 (2020). https://doi.org/10.1007/s12038-020-0009-x

Dubey P. Study of silk fibroin protein refolding and its self assembly process (Doctoral dissertation) (2018). http://eprint.iitd. ac.in/bitstream/handle/12345678/7608/TH-5526.pdf? sequence $=2$ 